\title{
Las formas verbales en las biblias de Alba y Ferrara: ¿fidelidad al texto hebreo?*
}

\author{
Francisco Javier DEL BARCO DEL BARCO ** \\ Instituto de Filología - CSIC, Madrid
}

A pesar de que durante la Edad Media la Biblia fue traducida al castellano profusamente, ya fuera tomando como texto base la Vulgata o los originales en hebreo, arameo y griego, sólo han pervivido a las vicisitudes históricas unos pocos manuscritos. Uno de estos manuscritos es la Biblia de Alba (en adelante, BA), llamada así por pertenecer desde el s. XVIII a la casa ducal de Alba ${ }^{1}$. Traducida del hebreo por Mošé Arragel de Guadalajara para Luis de Guzmán, maestre de la orden de Calatrava, entre los años 1422 y 1430, de

\footnotetext{
* Este trabajo ha sido posible gracias a una ayuda de la Maurice Amado Foundation y The UCLA Center for Jewish Studies. Agradezco también a los profesores Luis Vegas Montaner y José Luis Girón Alconchel su ayuda de diversa índole en distintas etapas de este trabajo. Un resumen de este artículo fue presentado en el VI Congreso de Historia de la Lengua Española, celebrado en Madrid entre el 29 de septiembre y el 3 de octubre de 2003.

** delbarco@filol.csic.es

1 Antes perteneció a D. Gaspar de Guzmán, Conde-Duque de Olivares, y a su familia, por lo que el manuscrito también fue conocido como Biblia de Olivares: cfr. C.-O. NoRdSTRÖM, The Duke of Alba's Castilian Bible, Figura. Uppsala Studies in the History of Art. New Series 5 (Uppsala 1967) pág. 24.
}

Sefarad 64 (2004) págs. 243-267

(c) CSIC

ISSN 037-0894 
ella suele decirse que es una traducción «al estilo de la Vulgata» ${ }^{2}$, lo que en la práctica quiere decir que, a pesar de traducir del hebreo los textos del AT, Mošé Arragel utilizó o consultó también la $V u l$ gata. Puesto que el destinatario de la traducción era cristiano, la Biblia no debía ser exclusivamente para uso de judíos, lo que le da cierto carácter ecuménico ${ }^{3}$. El manuscrito se conserva en el Palacio de Liria de Madrid, residencia de los duques de Alba, y existe una única edición en dos volúmenes, de $1920^{4}$.

La Biblia de Ferrara (en adelante, BF) es la primera edición en castellano de una traducción completa de la Biblia hebrea a este idioma. Fue editada por Abraham Usque y Yom Tob Atías, también conocidos por sus nombres de conversos Duarte Pinel y Jerónimo de Vargas ${ }^{5}$, en la ciudad italiana de Ferrara en 1553. Es también, por tanto, obra de traductores judíos pertenecientes a la importante comunidad sefardí de Ferrara, adonde fueron a parar una parte de los judíos sefardíes expulsados del reino de Nápoles en $1541^{6}$. Editada

2 Cfr. M. LAZAR, «Ladinando la Biblia entre los sefardíes mediterráneos: Italia, Imperio Otomano y Viena», en Introducción a la Biblia de Ferrara: Actas del Simposio Internacional sobre la Biblia de Ferrara, ed. I. HASSÁN (Madrid 1994) pág. 357.

3 Esto se aprecia tanto en la traducción como en las glosas exegéticas que acompañan al texto. Sobre la historia de la composición de la BA, véase $S$. FELlous, Histoire de la Bible de Moïse t.rragel: Quand un rabbin interpréte la Bible pour les chrétiens (París 2001).

4 Biblia (Antiguo Testamento) traducida del hebreo al castellıno por Rabi Mose Arragel de Guadalfajara y publicada por el duque de Berwick y de Alba, 2 vols., (Madrid: Imprenta Artística, 1920). Recientemente se ha realizado la digitalización de esta edición en el Instituto de Filología del CSIC, en Madrid, para un más fácil acceso y manejo del texto por parte de los investigadores. Junto a esta edición, existe un facsímil que va acompañado de un volumen de estudios y artículos: J. SCHONFIELD (ed.), La Biblia de Alba. An Illustrated Manuscript Bible in Castilian, with Translation and Commentaries by Rabbi Moses Arragel, 2 vols. (Madrid 1992).

5 Jerónimo de Vargas pudo haberse llamado, en realidad, Álvaro Vargas: cfr. A. LEONI, «New information on Yom Tov Atias (alias Alvaro Vargas), Co-publisher of the Ferrara Bible», Sefarad 57 (1997) págs. 271-276.

6 «Tras la expulsión de los judíos del reino de Nápoles en 1541, muchos sefardíes decidieron trasladarse a Ferrara, en el ducado de Este, respondiendo a la invitación de los duques, que ya hacía tiempo habían mostrado una actitud benévola hacia los 
bajo los auspicios del duque de Ferrara, los traductores pretendían que se convirtiera en versión de referencia para los judíos sefardíes, pero al mismo tiempo que fuera utilizada de manera general como la versión castellana más autorizada de la época, dada la importancia del español en Italia y en el panorama internacional europeo durante el s. XVI.

BA y BF son dos puntos culminantes en una tradición muy antigua de traducciones bíblicas. J. Llamas, antiguo bibliotecario del Monasterio de El Escorial, estudió los diferentes manuscritos bíblicos castellanos que se hallan en esta biblioteca ${ }^{7}$, y más recientemente M. Lazar ha establecido, dentro de lo posible, las diferentes relaciones de interdependencia entre las traducciones bíblicas castellanas anteriores al s. XVI que han llegado hasta nosotros ${ }^{8}$. De entre todos ellos, los más antiguos, con la salvedad de las traducciones bíblicas de la Fazienda de Ultramar $^{9}$, son los mss. I-j-6 e I-j-8 de El Escorial, que forman una Biblia prácticamente completa del s. XIII. Ambos manuscritos son traducciones realizadas a partir de la Vulgata.

Del s. XIV se conservan los mss. complementarios I-j-5 e I-j-7 de El Escorial, traducidos del hebreo pero con un destinatario cristiano,

judíos españoles y los marranos»: cfr. A. TOAFF, «Los sefardíes en Italia y en Ferrara en el s. XVI», en Introducción a la Biblia de Ferrara, pág. 192.

7 J. Llamas estudia el ms. I-j-3 en «La antigua Biblia castellana de los judíos españoles», Sefarad 4 (1944) págs. 219-244; el ms. J-II-19 en «Nueva Biblia judía medieval romanceada», Sefarad 9 (1949) págs. 53-74; y los mss. I-j-5 y I-j-7 en «Antigua Biblia judía medieval romanceada», Sefarad 11 (1951) págs. 289-304.

8 Véase M. LAZAR «Ladinando...», especialmente págs. 352-362, y «La plus ancienne adaptation castillane de la Bible», Sefarad 22 (1962) págs. 251-295.

${ }^{9}$ La Fazienda de Ultramar es un itinerarium Terrae Sanctae que contiene las traducciones castellanas más antiguas de algunos textos de la Biblia. El ms. se encuentra en la biblioteca de la Universidad de Salamanca, catalogado con el n. ${ }^{\circ}$ 1.997: cfr. M. LAZAR, «La plus ancienne...», quien lo data en el s. XII; otros prefieren situarlo en el s. XIII: cfr. H. SANTIAGO, «Para una nueva edición de la 'Fazienda de Ultramar'», BRAE 260 (1993) págs. 533-551, y B. Z. KEDAR, «Sobre la génesis de la Fazienda de Ultramar», Anales de Historia Antigua y Medieval 28 (1995) págs. 131-136. 
así como el ms. I-j-3 de El Escorial, del que conservamos una copia del s. XV, para cristianos. El original, sin embargo, fue con seguridad netamente judío, ya que es traducción literal del texto masorético y divide el Pentateuco en las habituales perícopas o parašîyôt $\underline{t}$ de las Biblias hebreas ${ }^{10}$. Del s. XV, además de BA, conservamos varias traducciones completas e incompletas, de entre las cuales son traducciones del hebreo los mss. I-j-4 y J-II-19 de El Escorial; este último también es de carácter judío, puesto que incluye glosas provenientes del Targum y de la exégesis rabínica; asimismo son traducciones del hebreo el ms. 87 de la Real Academia de la Historia en Madrid, el ms. 10.288 de la Biblioteca Nacional de España, y las Biblias de Evora y Ajuda ${ }^{11}$.

Con la expulsión de los judíos de España y el asentamiento de una gran parte de ellos en el Imperio Otomano, comienza el ciclo de traducciones bíblicas sefardíes en el Mediterráneo oriental, cuya primera obra de envergadura es la edición del Pentateuco de Constantinopla en 1547, en judeoespañol aljamiado acompañado de los textos hebreo y griego, también aljamiado, pocos años antes de la edición de BF por parte de los sefardíes de Italia ${ }^{12}$. 225 .

10 Cfr. J. LlAmAS, «La antigua Biblia castellana...», especialmente págs. 222-

${ }^{11}$ Sobre este último ms., véase G. AVENOZA, La Biblia de A.juda y la megil lat Antiochus en romance, Biblioteca de Filología Hispánica 25 (Madrid 2001). Sobre las traducciones medievales romanceadas en general, véase M. MORREALE, "Vernacular Scriptures in Spain», en The Cambridge History of the Bible, vol. II, ed. G. H. LAMPE (Cambridge 1969) págs. 465-491. Una visión de conjunto actualizada sobre los diferentes manuscritos puede encontrarse en P. SÁNCHEZ-PRIETO BORJA, sub voce «Biblias romanceadas», en Diccionario filológico de literatura medieval española. Textos y transmisión, eds. C. Alvar y J. M. LuCía Megías (Madrid 2002) págs. 212-223.

12 Sobre la relación entre el Pentateuco de Constantinopla y las Biblias romanceadas medievales, véase L. Amigo, El pentateuco de Constantinopla y la Biblia medieval romanceada judeoespañola: criterios y fuentes de traducción (Salamanca 1983). 


\section{ROMANCEAMIENTOS BÍBLICOS, ESPAÑOL Y JUDEOESPAÑOL ${ }^{13}$}

La denominación de la lengua de las traducciones de la Biblia al castellano realizadas por judíos durante la Edad Media y la Edad Moderna es un problema muy debatido entre los especialistas del judeoespañol y de la lengua de este tipo de traducciones. Éstas se caracterizan por un método o técnica de traducción literal y servil, en mayor o menor medida según los casos, que H. Vidal Sephiha ha llamado «lengua calco» ${ }^{14}$, y I. Hassan «lengua hebraizante» ${ }^{15}$. Esta técnica de traducción fue utilizada por los judíos para facilitar el acceso al texto bíblico a los miembros de sus comunidades que no dominaban la lengua hebrea, y por esa razón el texto hebreo subyace de manera evidente detrás del texto traducido ${ }^{16}$. El carácter sagrado de la Biblia en el judaísmo hizo que la sintaxis hebrea fuera fielmente reproducida en la lengua receptora, y que incluso algunas características morfológicas y muchas léxicas de la traducción resultante no puedan ser comprendidas sin tener al lado el texto hebreo. Tal método no es exclusivo de los judíos españoles, pues también fue utilizado en la traducción de la Biblia al griego desde la versión de Aquila en el s. II d.C. ${ }^{17}$ Así, algunas de estas Biblias

${ }^{13}$ El estudio del judeoespañol y de su corpus literario es una extensa disciplina de la filología hispánica que menciono aquí sin ánimo de intromisión en un campo que me es ajeno, con el único fin de establecer los límites y características de los romanceamientos bíblicos realizados por judíos.

${ }^{14}$ Cfr. H. Vidal SePhiHa, «Caracterización del ladino de la Biblia de Ferrara», en Introducción a la Biblia de Ferrara, pág. 300. Las tesis principales de este autor están expuestas en Le ladino, judéo-espagnol calque: Deutéronome, versions de Constantinople (1547) et de Ferrare (1553). Edition, étude linguistique et lexique (París 1973).

${ }^{15}$ Cfr., por ejemplo, I. HASSÁN, «Dos introducciones a la Biblia de Ferrara», en Introducción a la Biblia de Ferrara, pág. 31.

16 D. Bunis resume en seis puntos los principios fundamentales de esta técnica de traducción. Véase D. BUNIS, «Tres formas de ladinar la Biblia en Italia en los siglos XVI-XVII», en Introducción a la Biblia de Ferrara, págs. 322-323.

17 Según N. Fernández Marcos, «Esta técnica de traducción [palabra por palabra] se ha mantenido constante en la tradición judía grecoparlante que va desde el traductor Aquila en el s. II E. c. hasta el Pentateuco de Constantinopla (1547)»: cfr. N. Fernández MARCos, «La Biblia de Ferrara y sus efectos en las traducciones bíblicas al español», en Introducción a la Biblia de Ferrara, pág. 447. 
presentan el texto hebreo en columna paralela (como el Pentateuco de Constantinopla, que además incluye una traducción en griego), y muchos textos bíblicos y parabíblicos contienen glosas judeoespañolas con el único fin de ayudar a entender el texto hebreo.

Por otra parte, la lengua vernácula judeoespañola empezará a tener carácter propio desde finales del s. XVI ${ }^{18}$, y desarrollará una etapa brillante de producción literaria hasta el s. XIX, época en la que comenzará su decadencia como lengua hablada. Es, por tanto, lengua vernácula hablada con producción literaria, mientras que la lengua de las traducciones bíblicas es sólo escrita y condicionada por el método de traducción heredado desde la Edad Media. H. Vidal Sephiha reserva el término «ladino» para denominar a la lengua servil de las traducciones de la Biblia, mientras que para la lengua vernácula reserva el término de «judesmo» ${ }^{19}$. Otros especialistas opinan que la lengua de las traducciones bíblicas se diferencia de la vernácula solamente en su mayor uso de la técnica del calco, técnica que por otra parte no descartan, aunque en menor grado, para la lengua hablada. Así opina, por ejemplo, I. Hassán, quien propone el nombre genérico de «lengua sefardí» o «español judío» para el judeoespañol en general, y el de «lengua sefardí hebraizante» para la lengua de las traducciones bíblicas realizadas por judíos sefardíes ${ }^{20}$. Con esta terminología se propone establecer claramente que la lengua de las traducciones bíblicas no es una lengua diferente, sino que es el resultado de aplicar un método de traducción que se caracteriza por su lenguaje hebraizante y servil con respecto del hebreo. En cuanto al término «ladino», Hassán lo defiende como el término utilizado por los hablantes de judeoespañol para referirse a su lengua, tanto la vernácula como la servil de las traducciones bíblicas. M. Lazar coincide en denominar «ladino» a toda la lengua judeoespañola, aunque pone especial énfasis en resaltar el carácter judío de esta lengua, que es, en su opinión, lo que da a lo que denomina

\footnotetext{
18 Sobre este proceso, véase L. Minervini, «La formación de la koiné judeoespañola en el siglo XVI», Révue de Linguistique Romane 66 (2002) págs. 497-512.

19 Con la grafía džudezmo. Véase nota 14.

20 Véase nota 15.
} 
«lenguas judías» su caracterización propia, al igual que se lo da al judeoárabe o al yiddish ${ }^{21}$.

El diccionario de la RAE recoge bajo el término «ladino», además de otras, las siguientes acepciones ${ }^{22}: \ll 8$. Filol. Lengua religiosa de los sefardíes; es calco de los textos bíblicos hebreos y se escribe con letras latinas o con caracteres rasíes. \| 9. Filol. Dialecto judeoespañol de Oriente».

Hay que enfatizar de nuevo que la lengua vernácula de los judíos españoles no se convierte en lengua diferenciada hasta el momento en que el judeoespañol se configura como variedad distinta del español peninsular a finales del s. XVI. Una de las razones más importantes que suele esgrimirse para explicar la separación de esta variedad del español es la falta de contactos entre España (y el español peninsular) y las comunidades sefardíes del Imperio Otomano desde la expulsión en $1492{ }^{23}$. Como se ha dicho antes, el Imperio Otomano acogió a la mayor parte de los sefardíes expulsados de España en 1492 que no quisieron convertirse al cristianismo. Su lengua, por tanto, no participó de la importante transformación del español de los ss. XVI y XVII, y de ahí que tradicionalmente se la haya calificado de arcaica ${ }^{24}$.

$21 \ll(\ldots)$ cuando empleamos el término de judeo-español, o ladino, para denominar la lengua semitizada de los judíos oriundos de España, no lo limitamos a sus traducciones de textos bíblicos y parabíblicos del hebreo, por más que ellos utilicen más que otros traductores una técnica o sistema de literalidad (...). El judeoespañol, o ladino, (...) es una lengua romance judía, y como tal uno puede discutir de ella como medieval o arcaica, clásica o moderna, etc., independientemente de su empleo verbal o escrito, popular o literario, y de su utilización en una creación original o en una obra de traducción.» Cfr. M. LAzAR, «Ladinando...», pág. 349.

22 Diccionario de la lengua española (21 ${ }^{\mathrm{a}}$ ed. Madrid 1992).

23 En algunos casos desde las matanzas de 1391, fecha en la cual una buena parte de judíos españoles salieron ya de la Península Ibérica.

24 «Característico del judeo-español es su extraordinario arcaísmo»: cfr. R. LAPESA, Historia de la lengua española ( $9^{\mathrm{a}}$ ed. Madrid 1981) pág. 527. «(...) el carácter más interesante del habla judeoespañola: su enorme arcaísmo»: cfr. A. ZAMORA ViCEnTE, Dialectología española (2 $2^{\mathrm{a}}$ ed. Madrid 1967) pág. 351. Sin embargo, la investigación más reciente se opone, con razón, a calificar de arcaísmo lo que en realidad no es más que el resultado de una evolución lingüística distinta 
Podemos, pues, concluir que la lengua de las traducciones bíblicas responde a un método de traducción específico que usaron tanto los judíos españoles, antes de que el español que ellos hablaban se diferenciara del español peninsular, como los sefardíes, y que no constituye lengua en sí misma, porque no es un sistema lingüístico completo. Esta lengua es sólo escrita y debe considerarse, por tanto, una variante judía hebraizada de la lengua española si tratamos con textos anteriores al s. XVI, o de la judeoespañola si tomamos textos posteriores a las últimas décadas de ese mismo siglo. En otras palabras, la lengua de las traducciones bíblicas es el resultado de aplicar el método de traducción literal a los textos bíblicos y parabíblicos hebreos cuando se vierten al español o al judeoespañol. Por esta razón, no se puede considerar la lengua de las traducciones bíblicas como un sistema lingüístico completo diferente del español o del judeoespañol vernáculos.

\section{ASPECTOS SOCIOLINGÜÍSTICOS DE ALBA Y FERRARA}

Al tratar de la lengua de $\mathrm{BA}$ y $\mathrm{BF}$, es necesario hacer algunas precisiones sociolingüísticas para entender en toda su extensión el español que representan ambas Biblias. BA data del primer tercio del s. XV, antes de la expulsión de los judíos de España pero después de las matanzas de 1391, fecha tras la cual un número considerable de judíos reacios a la conversión salieron de España. R. Lapesa ${ }^{25}$ considera la posibilidad de que ya en la Edad Media la lengua española vernácula de los judíos de la Península tuviera ciertas características propias diferenciadas del español de los no judíos, debido en gran parte a la siempre presente influencia del hebreo y al papel central de los textos sagrados en la vida judía; por

\footnotetext{
a la del español peninsular: cfr. R. PENNY, «Dialect Contact and Social Networks in Judeo-Spanish», Romance Philology 46 (1992) págs. 125-140; IDEM, «La innovación fonológica del judeoespañol», en Actas del II Congreso Internacional de Historia de la Lengua Española, vol. III, eds. M. ARIZA et al. (Madrid 1992) págs. 251-257.

25 R. LAPESA, Historia de la lengua española, págs. 525-526.
} 
esta razón parece plausible hablar de un español judío ya desde la Edad Media, aunque no de judeoespañol ${ }^{26}$. En el caso de BA, hay que considerar el hecho de que ciertas características judías en el lenguaje pueden estar atenuadas, ya que el destinatario de la traducción era cristiano; por otra parte, para evitar posibles hostilidades antijudías, Mošé Arragel utilizó la Vulgata como fuente en numerosos pasajes, con lo que la fidelidad al texto hebreo a veces se desvanece.

BF data de mediados del s. XVI, es decir, un siglo más tarde que BA, y presenta un escenario diferente, ya que es obra de judíos sefardíes pertenecientes a la comunidad de Ferrara. Los numerosos investigadores que han estudiado la lengua de esta Biblia coinciden en señalar que se trata del español del s. XVI ${ }^{27}$, aunque con algunos arcaísmos y con un reflejo evidente de que se ha utilizado el método de traducción literal o "palabra por palabra», como dicen los traductores en el título que dan a su obra ${ }^{28}$. Que el español de BF sea el del siglo al que pertenece es natural, puesto que los traductores, aun viviendo en Italia, no han perdido contacto con el español peninsular, ya que las relaciones entre Italia y España en el s. XVI eran muy estrechas. Por otra parte, tanto Abraham Usque como

\footnotetext{
26 M. Lazar defiende la teoría de la existencia de lo que llama «lenguas judías», y explica sus particularidades de la siguiente manera: «[Las lenguas judías] nacieron de una 'semitización' de las lenguas vernáculas por sus hablantes judíos en la diáspora, ocurrida en el proceso de 'trasladar' los textos bíblicos del hebreo a la lengua del territorio donde vivían y de enseñarlos en las escuelas sinagogales, así como en la composición de glosarios bíblicos bilingües que recogían las palabras difíciles.» Cfr. M. LAZAR, «Ladinando...», pág. 348. Sin embargo, es difícil aceptar que esas características conviertan a la lengua judía en cuestión en lengua diferenciada de la lengua madre de la que surge. En el caso del judeoespañol, eso sólo ocurre a partir de fines del s. XVI, cuando la lengua de los sefardíes del Imperio Otomano se ha configurado como sistema lingüístico diferenciado del español peninsular.

27 «(...) se puede decir que la Biblia de Ferrara básicamente está escrita en el español del s. XVI», en opinión de M. ÁLVAREZ et al., «La lengua castellana de la Biblia de Ferrara», en Introducción a la Biblia de Ferrara, pág. 522.

28 Biblia en lengua española traduzida palabra por palabra de la verdad hebrayca por muy excelentes letrados vista y examinada por el officio de la Inquisicion.
} 
Yom Tob Atías pertenecían a familias de conversos que habían permanecido en la Península Ibérica hasta finales del s. XV.

En opinión de D. Bunis, BF supone un episodio interesante que refleja la diferenciación lingüística existente entre los judíos conversos vueltos al judaísmo, como parece ser el caso de los traductores de Ferrara, y los judíos fieles a su fe que emigraron al Imperio Otomano, algunos de los cuales ya habían salido de la Península Ibérica antes de la definitiva expulsión de finales del s. XV ${ }^{29}$.

En la época de la expulsión, los judíos españoles se dividen en dos grandes grupos. Por un lado, los que rechazan la conversión al cristianismo y salen de España en dirección al Imperio Otomano y norte de África principalmente, pero también a Italia y Portugal. Estos judíos mantienen su español vernáculo, que a partir de entonces empezará a perder el contacto con el español peninsular, iniciando un proceso que culminará en la configuración del judeoespañol como lengua vernácula diferente del español peninsular.

Por otro lado, están los que aún permanecen en España después de convertirse al cristianismo y los que se convierten en Portugal. Muchos de ellos acabarán siendo expulsados o se irán por propia voluntad, con destino a Amsterdam, Italia u otras ciudades de Europa occidental, principalmente, mientras que una gran parte volverá de nuevo al judaísmo, como es el caso de los editores de BF. Durante su paso por el cristianismo, estos judíos debieron de hacer un esfuerzo lingüístico por eliminar de su lengua aquellas características que pudieran señalarlos como judíos, y una vez fuera de España, no perdieron contacto con el español peninsular ni con los importantes cambios lingüísticos que ocurrieron en los siglos XVI y XVII, porque el español era lengua internacional en Europa occidental. Aun después de volver al judaísmo, estos judíos sefardíes ya no hablaban exactamente la misma lengua que los sefardíes instalados en el Imperio Otomano; su lengua estaba más cerca del español

\footnotetext{
29 La siguiente exposición se basa en D. BuNIS, «Tres formas...», págs. 315345
} 
peninsular de la época. Por esta razón, R. Lapesa ${ }^{30}$ afirma que los sefardíes de Europa occidental no utilizaron una lengua muy diferente de la que se hablaba en la Península en los siglos XVI y XVII.

En Italia, ambos grupos de sefardíes coincidieron. Según Bunis, la intención de los traductores de BF era que ambos grupos pudieran reconocerse en la lengua utilizada, y que al mismo tiempo esta Biblia sirviera como versión castellana de referencia para los cristianos. De ahí que la lengua de Ferrara sea el español del s. XVI, pero con arcaísmos y giros propios que debían de utilizar los judíos antes de la expulsión, así como el uso de un método de traducción literal que entroncaba con la traducción judía medieval, pero también con una fidelidad al texto que satisficiera a los cristianos.

Por todo lo expuesto hasta aquí, la comparación de BA y BF, y la de éstas con el texto original hebreo, resulta un elemento fundamental para determinar el grado de fidelidad de las traducciones con respecto al texto hebreo, y cómo aquéllas reflejan el estado de la lengua española de los ss. XV y XVI.

\section{LA TRADUCCIÓN DE LAS FORMAS VERBALES}

Puesto que son numerosos los estudios dedicados al análisis de la lengua de $\mathrm{BA}$ y $\mathrm{BF}$, el estudio comparativo que aquí se presenta se va a centrar en uno de los aspectos sintácticos menos estudiado: el del uso de las formas verbales en comparación con el hebreo. Para ello se han escogido dos capítulos correspondientes a dos de los tipos de texto más frecuentes en la Biblia: 2 Sam 11 como ejemplo de prosa narrativa, y Amós 2 como ejemplo de poesía profética.

A grandes rasgos, desde un punto de vista morfológico, el hebreo posee dos formas personales, una de perfecto y otra de imperfecto, aunque debido a la existencia del llamado «waw consecutivo» o «conversivo», que se prefija a las formas antes mencionadas, hay que hablar de un sistema sintácticamente articulado alrededor de

\footnotetext{
${ }^{30}$ R. LAPESA, Historia de la lengua española, pág. 524, nota 1.
} 
cuatro formas personales: perfecto e imperfecto simples y estas mismas formas con waw consecutivo prefijado ${ }^{31}$. Según la teoría temporalista ${ }^{32}$, perfecto simple e imperfecto con waw consecutivo expresarían temporalidad pasada, mientras que imperfecto simple y perfecto con waw consecutivo expresarían temporalidad futura. La teoría aspectual ${ }^{33}$, por su parte, basa la oposición de significado en el aspecto perfectivo que representaría el perfecto simple, frente al aspecto imperfectivo, representado por el imperfecto simple. Las formas con waw consecutivo no tendrían un aspecto gramaticalizado, y su significado dependería en gran medida del contexto ${ }^{34}$.

Además de las formas mencionadas, el sistema verbal hebreo posee un repertorio de formas volitivas diferenciadas, entre las que están el cohortativo para la primera persona, el imperativo para la segunda, y el yusivo para la segunda y tercera personas. En cuanto a las formas no personales, el hebreo posee dos infinitivos, llamados constructo y absoluto, además de participio activo y pasivo. El participio activo es la forma que en hebreo moderno se utiliza como el equivalente al presente castellano. En la Biblia, sin embargo, además de funcionar como el participio de presente latino, expresa

31 Las formas con waw consecutivo sólo pueden ir en el comienzo de su oración.

32 Imperante en la gramática hebrea desde la Edad Media hasta el s. XIX.

33 A partir de S. R. DRIVER, A treatise on the use of the tenses in Hebrew and some other syntactical problems (Oxford 1874) y G. H. A. Von EwALD, Kritische Grammatik der hebräischen Sprache (Leipzig 1927), que se basan en el sistema verbal del griego clásico.

34 El significado de las formas verbales hebreas de la Biblia sigue siendo un tema muy debatido. Las teorías temporales y aspectuales dejan un gran número de casos sin explicar, por lo que en la actualidad se tiende a analizar el uso de las diferentes formas verbales como parte de una unidad de significado más allá de la oración, es decir, como parte de un segmento textual, entendido éste como una unidad de significado con una estructura formal determinada (análisis del discurso o lingüística textual). Desde este punto de vista, una forma verbal alcanzaría su pleno significado sólo como parte de un segmento textual, lo cual deja sin valor el análisis de las formas verbales que se realice exclusivamente en el reducido ámbito de su oración. 
simultaneidad con la forma verbal que le antecede, ya sea en un ámbito de temporalidad pasada, presente o futura ${ }^{35}$.

\section{a) Imperfecto consecutivo y perfecto simple}

En 2 Sam 11, capítulo que hemos escogido como paradigma de la prosa narrativa, el discurso narrativo en hebreo se articula mediante el uso de imperfectos consecutivos y perfectos simples desplazados del inicio de la oración ${ }^{36}$. Tanto BA como BF traducen ambas formas verbales por pretéritos perfectos simples castellanos. BA presenta, sin embargo, algunas excepciones a esta regla, y hay dos casos en que traduce el perfecto simple hebreo por pretéritos imperfectos castellanos. En ambos casos se trata de interpelaciones en estilo directo y no de la línea principal del discurso narrativo ${ }^{37}$ :

2 Sam 11,20: Maddûa' niggaštem 'el-ha 'îr l'hil-lahem.

BA: «e vosotros ¿porque tanto vos aplicauades a la cibdad a pelear $[\ldots] ? »$.

\section{Sam 11,21: Lammâ niggaštem 'el-hahômâ.}

BA: «e vosotros ¿por qual razon vos allegauades al muro?».

$\mathrm{BF}$, por el contrario, ofrece en ambos casos «allegastes», forma del pretérito perfecto simple.

35 El sistema verbal del hebreo bíblico tiene poco que ver con el del hebreo moderno. Este último posee un sistema verbal que se basa en el hebreo rabínico y en las lenguas europeas modernas.

${ }^{36}$ El lugar del verbo en la oración es relevante a nivel textual. Puesto que las formas con waw consecutivo sólo pueden ir en el inicio de la oración, las formas desplazadas tienen que ser siempre perfecto o imperfecto simple.

${ }^{37}$ Los ejemplos comparativos presentan la transliteración del texto hebreo bíblico, en versión de BHS (K. Elliger, y W. RudOLPH [eds.], Biblia Hebraica Stuttgartensia [4a ed. Stuttgart 1990]). El texto de BF corresponde al editado por M. LAZAR (ed.), The ladino Bible of Ferrara (Culver City 1992), y el de BA a la edición de 1920 mencionada más arriba. 
En el texto de Amós 2, encontramos algunos perfectos simples e imperfectos consecutivos hebreos, traducidos regularmente por pretérito perfecto simple castellano en el caso de BF. BA sigue también esta tónica general, pero presenta de nuevo una excepción. Así, en la recurrente oración introductoria de las palabras de Dios koh 'amar $Y H W H, \mathrm{BF}$ traduce literalmente «Assi dixo Adonay», con el verbo en perfecto simple, mientras que BA interpreta el perfecto simple hebreo como atemporal, puesto que se trata de las palabras de Dios, y traduce «Asy dize el Señor», con el verbo en presente.

El sistema verbal hebreo de la Biblia no tiene una forma específica para expresar el antepasado o pluscuamperfecto, por lo que recurre al perfecto simple para expresarlo. Ahora bien, esta forma expresa también otras relaciones temporales, generalmente en el ámbito del pasado, por lo que el concepto de antepasado debe discernirse del contexto, ya sea semántico, ya sea por una disposición sintáctica específica del segmento textual en el que la forma se inserta. En 2 Sam 12,3 encontramos un claro ejemplo de antepasado:

2 Sam 12,3: W'laraš 'ên-kol kî̀ 'im-kibśâa 'ahạ q tannâ 'ašer qanâ.

F. Cantera ${ }^{38}$ traduce este perfecto simple por pluscuamperfecto, puesto que el contexto semántico así lo exige: «mientras el pobre nada poseía si no era una sola corderilla, que había comprado». BF se mantiene fiel a su regla y traduce perfecto simple hebreo por pretérito perfecto simple castellano, manteniendo, además, el mismo orden de palabras del texto hebreo: «Y al pobre no algo, que saluo cordera vna pequeña que compro». BA vuelve a presentar otra excepción a la regla general, y ofrece la forma compuesta del pretérito pluscuamperfecto de indicativo en vez de usar el perfecto simple o la forma comprara, que en el s. XV aún se usaba con valor plus-

38 F. CANTERA, Sagrada Biblia (2 ${ }^{\mathrm{a}}$ ed. Madrid 1979). 
cuamperfecto ${ }^{39}:$ «e el pobre cosa non tenia, saluo vna pequeña corderuela que auia conprado». Ahora bien, no sabemos si usa esta forma porque percibe el valor de antepasado en el perfecto hebreo, o porque en este caso concreto sigue al texto latino de Vulgata que ofrece emerat, pretérito pluscuamperfecto de indicativo.

\section{b) Perfecto consecutivo e imperfecto simple}

El discurso predictivo, propio de la profecía bíblica, está fundamentalmente articulado por el perfecto consecutivo y el imperfecto simple, este último por lo general desplazado del inicio de la oración. BF tiende a traducir ambas formas por futuros, salvo algunas excepciones que veremos en seguida. BA, si bien también traduce algunas de estas formas por el futuro castellano, ofrece un repertorio de formas verbales más variado para poder expresar con la sintaxis castellana la multiplicidad de significados que el hebreo expresa con estas dos formas.

En Amós 2, tanto BF como BA traducen las dos formas hebreas que acabamos de mencionar por futuros castellanos, excepto en el segmento textual de los vers. 7-8. Este pasaje está introducido por una oración de participio seguido de oraciones con imperfecto simple desplazado del inicio de la oración. Tal estructura, de acuerdo con las teorías de lingüística textual aplicadas al hebreo bíblico, conforma un segmento explicativo que no incide en la orientación temporal de las acciones expresadas, sino que simplemente las enumera como características de uno o varios personajes del argumento ${ }^{40}$. De ahí

39 «La forma cantara es muy frecuente con valor de pluscuamperfecto de indicativo (...) en la lengua antigua. (...) ya está en desuso en el siglo XVI»: cfr. R. LAPESA, Estudios de morfosintaxis histórica del español (Madrid 2000) págs. 869870 . De aquí se deduce que en el s. XV todavía podía utilizarse, aunque es posible que sonara arcaica.

${ }^{40}$ Un análisis sintáctico y textual del pasaje completo puede encontrarse en F. J. DEL BARCO, Profecía y sintaxis: el uso de las formas verbales en los Profetas Menores preexílicos (Madrid 2003) págs. 90-93. 
que BA y BF traduzcan los imperfectos simples de estas oraciones por presentes castellanos ${ }^{41}$ :

Am 2,7: Hašo'afîm 'al-'afar-'eres bro'š dal.lîm w'derek

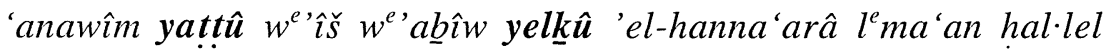
'et-šem qodšî.

BA: «Que asoplan sobre poluo tierra en cabo de los mesquinos, e la via de los humilles declinan, e fiio e padre van a la mançebia a fin de menospreçiar el mi santo nonbre».

BF: «Los soruientes sobre poluo de tierra en cabeça de mendigos, y carrera de humildes atuerçen; y varon y su padre andan a la moça, para abiltar nombre de mi santidad».

Otra excepción comprensible en que BF no traduce imperfecto simple por futuro es el de Amós 2,12. El texto hebreo dice: Lo' tinnab' $\hat{u}$ (imperativo negativo).

El mandato negativo se expresa en hebreo generalmente mediante dos estructuras. Los mandatos que se refieren a una acción y a un momento determinados utilizan la negación 'al más yusivo. Los mandatos que se refieren a órdenes permanentes o eternas utilizan la negación $l o$ ' más imperfecto simple. En este caso, el texto hebreo nos presenta un mandato permanente en estilo directo.

Así, BF traduce «no prophetizedes», usando para el imperativo negativo presente de subjuntivo castellano, en vez del futuro que suele ofrecer cuando hay imperfecto simple hebreo. La mayor libertad a la hora de traducir que muestra BA se ve en la traducción de este mandato. BA ofrece: «que non prophetizasen», cambiando en indirecto el estilo directo del texto hebreo, por lo que la forma verbal castellana tiene también que cambiar a la que corresponda, en este caso imperfecto de subjuntivo ${ }^{42}$.

\footnotetext{
41 En cuanto al participio que inicia el versículo, BF aplica la equivalencia y lo traduce como participio de presente, mientras que BA ofrece tiempo presente, de acuerdo con el resto del segmento textual. Véase infra, sobre el participio.

${ }^{42}$ No puede ser influjo de Vulgata porque ésta ofrece «Ne prophetetis», en estilo directo.
} 
En 2 Sam 11, BF traduce sistemáticamente imperfecto simple y perfecto consecutivo hebreos como futuros castellanos, ya sea en indicativo o en subjuntivo, mientras que BA no se ciñe a este esquema y utiliza un elenco de formas más variado para lograr una correcta expresión según la sintaxis castellana del s. XV.

En el vers. 10, el rey pregunta a Urías por qué no ha ido a su casa a descansar como él le había ordenado, y en el vers. 11 Urías le responde que, estando todos sus compañeros preparándose para la batalla, cómo va a ir él a descansar:

2 Sam 11,11: Wa'anî 'ab ôo' 'el-bêtî̀ le'ekol welištôt.

Que, literalmente, quiere decir: «¿y yo iré a mi casa a comer y beber?».

BA ofrece: «[el archa del testamento e Israhel e Iuda habitan en choças, e my señor Ioab e los sieruos del mi señor estan sobre fazes del canpo asentados,] e ¿estaua en razon que yo a mi casa fuese a comer e beuer[...]?». Podemos interpretar, a mi entender, que quiere decir algo así como « ¿acaso sería normal que yo hubiera ido a mi casa a comer y beber?», orientando la forma verbal hacia el pasado. BF aplica la literalidad y traduce imperfecto simple hebreo por futuro: «yo verne a mi casa a comer y a beuer [...]?».

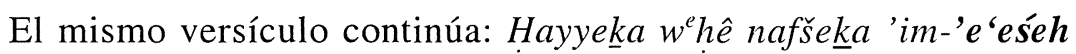
'et-haddabar hazzeh.

BF traduce el imperfecto simple hebreo por futuro castellano: «Por tu vida y por vida de tu alma, no fare la cosa esta». Vemos, sin embargo, que BF traduce correctamente la oración de juramento con la partícula condicional 'im por una oración negativa, aunque así no respete la literalidad palabra por palabra. BA traduce: «Par la tu vida, e par la vida de tu anima, que non lo faga», donde en vez de utilizar el futuro castellano prefiere expresar un matiz volitivo en la oración negativa y utiliza el presente de subjuntivo castellano.

BF muestra la misma literalidad con los perfectos consecutivos, que traduce sistemáticamente por futuros castellanos, aun cuando la sintaxis castellana correcta exigiría otras formas. 
En 2 Sam 11,15 el texto hebreo ofrece una oración de imperativo seguida por tres oraciones con perfectos consecutivos. El primero de estos perfectos consecutivos expresa un mandato atenuado sin la violencia de la orden directa que expresaría otro imperativo, mientras que los otros dos perfectos consecutivos son resultativos, como vamos a ver en seguida:

2 Sam 11,15: Hab̂u 'et-'ûrîyâ 'el-mûl penê hammilhamâ hahazaq $\hat{a}$ $w^{e}$ šabtem me'aharayw w' nikkâ wamet.

La traducción de F. Cantera ${ }^{43}$ expresa con acierto los diferentes valores de las formas verbales. Dice: «Poned a Urías en vanguardia donde más recia sea la lucha y retiraos de su espalda, para que sea herido y muera».

En efecto, F. Cantera traduce el primer perfecto consecutivo como un imperativo. Ya hemos dicho antes que este perfecto consecutivo expresa un mandato atenuado. En la narrativa hebrea, uno o varios perfectos consecutivos tras un primer imperativo que inicie un segmento textual tienen justamente esa función ${ }^{44}$, que es la que observamos en el versículo que nos ocupa. Los otros dos perfectos consecutivos tienen un matiz resultativo o de finalidad, como lo refleja la traducción de Cantera.

BF ofrece la siguiente traducción: «Poned a Uriah a escuentra fazes de la pelea fuerte, y tornaruosedes ${ }^{45}$ de empos el, y sera ferido y morira».

43 F. CANTERA, Sagrada Biblia.

44 Véase R. LONGACRE, «Discourse Perspective on the Hebrew Verb: Affirmation and Restatement», en Linguistics and Biblical Hebrew, ed. W. BodINE (Winona Lake 1992) págs. 186-188.

45 M. Morreale explica que los futuros en BF aparecen unidos excepto en presencia del pronombre, que los hace aparecer separados; este caso sería una excepción, porque a pesar de la presencia del pronombre la forma está unida: cfr. M. MORREALE, «La Biblia de Ferrara y los romanceamientos medievales: 2Sm 22 y Ps 18», en Introducción a la Biblia de Ferrara, pág. 94. En BA encontramos, sin embargo, «retraervos hedes». 
Los tres futuros castellanos se corresponden con los tres perfectos consecutivos hebreos, por lo que parece que lo más importante para los traductores de BF ha sido ofrecer una misma correspondencia de la forma hebrea con una única forma castellana, en detrimento de una matización más detallada del texto. En BA encontramos: «Pon tu a Vrias delantero de la batalla mas rezia, e retraervos hedes çaga el, por tal que lo fieran e muera». Aquí observamos que, al igual que en $\mathrm{BF}$, el primer perfecto consecutivo se traduce por futuro castellano, pero los dos últimos muestran en castellano un giro resultativo, expresado con presentes de subjuntivo.

\section{c) Participio}

De entre las formas no personales, el participio es la más importante, tanto por su frecuencia de uso para articular el discurso en hebreo bíblico como por las traducciones que ofrecen las versiones castellanas de Alba y Ferrara ${ }^{46}$.

$\mathrm{BF}$ sigue su tónica general de literalidad y traduce los participios hebreos por participios de presente castellanos. Esta traslación automática presenta numerosos problemas, ya que el participio hebreo se usa con mucha frecuencia debido a sus funciones sintácticas, mientras que el participio de presente castellano es una forma rara cuyo uso sintáctico original latino se suple con el uso de oraciones subordinadas y de otras formas verbales.

\footnotetext{
${ }^{46}$ Sobre la morfología del participio de presente en BF, M. Morreale explica las formas del masculino singular tipo «están» = 'estante, el que está', como formas apocopadas (estante>estant>están): cfr. M. MORREALE, «Introducción...», pág. 93. Sin embargo, M. Álvarez, M. Ariza y J. Mendoza ven difícilmente aceptable que exista apócope extrema en pleno s. XVI, por lo que sugieren que ese tipo de formas puedan descender del nominativo singular, en vez del acusativo (sapiens $>$ sabién), lo cual tampoco deja de ofrecer no pocas dificultades: cfr. M. ÁlvAREZ et al., «La lengua castellana...», págs. 512-516, sobre este punto en particular y sobre el verbo en $\mathrm{BF}$ en general.
} 
A grandes rasgos, puede decirse que el participio hebreo tiene dos funciones básicas. Por un lado, se utiliza como equivalente de la oración de relativo cuando el sujeto de ésta es el antecedente que se encuentra en la oración principal. En estos casos suele ir precedido del artículo determinado prefijado. Por otro lado, las oraciones de participio expresan en algunos tipos de discurso y en un contexto determinado una temporalidad simultánea al tiempo principal del discurso, que puede estar situado en el ámbito del pasado, del presente o del futuro. Es en este segundo uso, justamente, donde la correspondencia con el participio de presente castellano que ofrece BF llama más la atención.

En 2 Sam 11,1 encontramos una oración de participio dentro de un texto en el ámbito temporal del pasado: $W^{e} \underline{d} a w i \underline{d}$ yôše b bîušalaim.

BF: «y Dauid están en Yerusalaim».

BA: «e Dauid estaua en Ierusalem».

Frente al participio que ofrece BF, BA traduce por la forma correspondiente para expresar simultaneidad en el ámbito del pasado, en este caso el imperfecto de indicativo.

Un caso muy parecido, pero en el ámbito temporal del presente, lo encontramos en el vers. 11, donde se utilizan varios participios para expresar simultaneidad con el momento del discurso:

2 Sam 11,11: Ha'arôn weyiśra'el wîhûdâ yošbîm bassukkôt

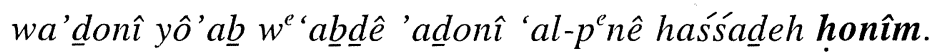

BF: «[Si] la arca y Ysrael y Yehudah estantes en cabañas, y mi señor Yoab y sieruos de mi señor sobre fazes del campo posantes».

BA: «[Señor] el archa del testamento e Israhel e Iuda habitan en choças, e my señor Ioab e los sieruos del mi señor estan sobre fazes del campo asentados».

$\mathrm{BF}$ vuelve a utilizar los participios de presente, mientras que BA ofrece la forma correspondiente para expresar simultaneidad en el ámbito del presente, que es el presente de indicativo castellano. 
Sin embargo, BF presenta una excepción en su rigidez de correspondencias. Esta excepción es un caso de participio que expresa simultaneidad en el ámbito del pasado. Ambas versiones, BF y BA, traducen por la correspondiente forma de simultaneidad, imperfecto de indicativo castellano, y no por participio de presente.

2 Sam 11,4: W'ĥ̀' mitqaddešet mittum'atah.

BF: «Y ella se santificaua de su enconamiento».

BA: «la qual se santificaua de su inmundiçia».

En Amós 2 existe un caso en que la oración de participio se encuentra en el ámbito del futuro. Es un segmento textual que comienza con la oración de participio ${ }^{47}$, le sigue una oración de perfecto consecutivo y después una serie de oraciones con imperfectos simples desplazados del lugar inicial de sus respectivas oraciones ${ }^{48}$. Esta estructura es una variante del discurso predictivo profético ${ }^{49}$, que presenta una clara orientación temporal futura. La oración de participio en cuestión es la siguiente:

Am 2,13: Hinneh 'anokî $\boldsymbol{m} \boldsymbol{e}^{\text {'îq }}{ }^{50}$ tahtêkem.

BF: «He yo apretán en vuestro lugar».

BA: «Ahe que yo apretaré yuso de vos bien».

BA, con el uso del futuro castellano, expresa correctamente la orientación temporal futura que tiene todo el segmento textual, mientras que BF ofrece, de nuevo, participio de presente.

\footnotetext{
${ }^{47}$ La oración de participio va introducida por la partícula hinneh y constituye la apódosis de un esquema bimembre. Véase nota 40.

${ }^{48}$ Para introducir en ese lugar destacado el elemento nuevo que se presenta en cada oración, que en este caso es el sujeto, y no el verbo.

49 Sobre éste y otros tipos de discurso en la profecía bíblica, véase F. J. DEL BARCO, Profecía y sintaxis, págs. 236-241.

${ }^{50}$ La raíz ' $w q$, que ambas versiones traducen como 'apretar', significa más propiamente 'hender'.
} 
d) Infinitivo

El infinitivo es otra forma no personal cuyas funciones sintácticas no coinciden con las del infinitivo español. El infinitivo hebreo posee dos formas diferentes: una de infinitivo absoluto y otra de infinitivo constructo. La primera de ellas se usa con bastante frecuencia antepuesto a una forma verbal personal de la misma raíz, con un significado de intensidad. La segunda de las formas es la más frecuente y suele llevar prefijada una de las preposiciones monoconsonánticas, que son $k^{e}$ 'como', $b^{e}$ 'en' y $l^{e}$ 'para'. Con la preposición $l^{e}$ 'para' prefijada, el infinitivo constructo expresa finalidad. Con alguna de las otras dos preposiciones, el infinitivo expresa una circunstancia temporal. Cuando esto es así, la única forma de poder traducir correctamente al castellano es utilizando una oración subordinada adverbial de tiempo, sobre todo si el infinitivo lleva sufijado algún pronombre personal, que ejerce la función de sujeto o de complemento directo del infinitivo. 2 Sam 11 nos ofrece algunos ejemplos de lo que acabamos de decir.

2 Sam 11,16: Way'hî bišmôr yô'ab 'el-ha 'îr.

BA: «E auino asy que Ioab, guardando a la çibdat, [puso a Vrias en el logar que entendio que eran ende los mas fuertes omnes]».

BF: «Y fue en guardar Yoab a la ciudad, [y puso a Uriah al lugar que supo que varones de fuerça alli]».

BF traduce literalmente todo el versículo, y ofrece en castellano una equivalencia exacta de la expresión temporal hebrea, preposición más infinitivo, a pesar de que tal sintaxis no es correcta en castellano. BA, por el contrario, se vale de una oración de gerundio para ofrecer una expresión temporal equivalente a la que en hebreo tiene el infinitivo constructo precedido de la preposición $b^{e}$.

Otro ejemplo interesante lo encontramos en el vers. 19, donde el primer infinitivo constructo que encontramos, además de la proposición prefijada; lleva un pronombre personal sufijado. 
2 Sam 11,19: K' kal-lôtka 'et kol-dibrê hammilhamâ l' $\mathbf{l}^{e}$ abber 'elhammelek.

BA: «Des que ouieres conplido de contar el negoçio de la batalla al rey».

BF: «Como tu atemar a todas las palabras de la pelea para fablar al rey».

La literalidad extrema de BF hace casi incomprensible la traducción a menos que se conozca el texto hebreo subyacente. La estructura hebrea de infinitivo con preposición antepuesta y pronombre sufijado es traducida literalmente, como el resto del versículo. BA utiliza, por el contrario, una oración subordinada que haga comprensible en castellano lo que expresa la estructura hebrea. Hay que señalar, además, que BA utiliza aquí una forma compuesta con el verbo haber como auxiliar, aunque cabe la duda, de nuevo aquí como en otros pasajes, de que debajo de este futuro compuesto de subjuntivo lo que subyace es el futuro perfecto compleveris que ofrece Vulgata $^{51}$.

\section{CONCLUSIONES}

Los ejemplos presentados muestran claramente que la $\mathrm{BF}$, salvo contadas excepciones, tiene un sistema de correspondencias entre las formas verbales hebreas y las castellanas. Imperfecto consecutivo y perfecto simple son traducidos sistemáticamente por pretéritos perfectos simples. Perfecto consecutivo e imperfecto simple se corresponden con formas de futuro, ya sea de indicativo o de subjuntivo. En cuanto a las formas no personales, participios e infinitivos hebreos son traducidos por sus correspondientes castellanos,

\footnotetext{
51 Sin embargo, el hecho de que el traductor haya utilizado una forma compuesta indica que se ajusta a los usos lingüísticos del español del s. XV. En otras palabras, las formas verbales utilizadas en BA parecen reflejar el sistema verbal español de la primera mitad de ese siglo.
} 
aun cuando las funciones sintácticas de estas formas en hebreo y en español son, en algunos casos, muy diferentes. Tal correspondencia de formas hace difícil, en ocasiones, la comprensión de la traducción a menos que se conozca el texto hebreo subyacente, y condiciona en gran medida la elección de formas castellanas. Sólo algunas excepciones, y la posibilidad de elección entre los distintos modos o aspectos, cuando éstos existen, dan cierto margen de elección a los traductores sobre las reglas que ellos mismos se impusieron. El sistema de correspondencias que se utiliza en BF impide, por tanto, que el sistema verbal del español del s. XVI se muestre de manera natural en este texto.

BA ofrece una traducción mucho menos literal que BF, y no parece haber utilizado ningún sistema de correspondencias rígido entre las formas verbales hebreas y las castellanas. Por otra parte, hay que tener en cuenta que en algunos pasajes el texto subyacente es el de la Vulgata más que el propio texto hebreo masorético. La impresión es que Moše Arragel se ha preocupado más por presentar un texto que expresara correctamente en castellano lo que él entiende que dice el texto bíblico. Para ello se vale de todo el elenco de formas verbales castellanas de que dispone, y las utiliza según el sistema verbal del español del s. XV. Un ejemplo de ello es que encontramos formas que en ese momento se están haciendo cada vez más frecuentes en comparación con la lengua antigua, como son las formas compuestas. Su sistema de traducción, por tanto, tiene como prioridad la comprensión de un pasaje completo o de una unidad textual primero, y la traducción de ese pasaje a un castellano gramaticalmente correcto después. 


\section{RESUMEN}

Este artículo se centra en el estudio de textos narrativos y proféticos de las biblias de Alba y Ferrara y en su comparación con el original hebreo. El fin de tal estudio es hallar las claves de sus sistemas de traducción dentro de la tradición judía medieval de traducciones bíblicas. Uno de los aspectos más destacables es la traducción de las formas verbales del hebreo bíblico al español. El interés en este punto está en ver cómo los traductores entienden el sistema verbal del hebreo bíblico y lo vierten al castellano de los ss. XV y XVI, así como en las diferencias de traducción existentes entre ambas biblias, que será ilustrado con numerosos ejemplos. El aspecto lingüístico se presenta aquí en su contexto sociológico y cultural, como factores que influyen en los métodos de traducción.

PALABRAS ClAVE: Biblia hebrea, Biblia de Alba, Biblia de Ferrara, métodos de traducción, verbo hebreo.

\section{SUMMARY}

This article focuses on the study of narrative and prophetic texts in the Ferrara and Alba Bibles and on their comparison to the Hebrew original. The aim of such a study is to find the keys to their systems of translation within the medieval Jewish tradition of Biblical translations. One of the most remarkable aspects is the translation of the verbal forms from Biblical Hebrew to Spanish. What is interesting about this aspect is how the translators understand the verbal system of Biblical Hebrew and how they converted it into $15^{\text {th }}$ and 16th century Castilian, as well as the existing differences in the translation of both bibles; this fact will be illustrated with abundant examples. The linguistic aspect is offered here in its sociological and cultural context, as factors that affect translation methods.

KEYWORDS: Hebrew Bible, Bible of Alba, Bible of Ferrara, translation methods, Hebrew verb. 